\title{
The Impact of Supplemental Instruction on the Learning Achievements and Attitudes of Organic Chemistry Students
}

\author{
Issa I Salame $1^{*}$
}

${ }^{1}$ The City College of New York of the City University of New York, UNITED STATES

*Corresponding Author: isalame@ccny.cuny.edu

Citation: Salame, I. I. (2021). The impact of supplemental instruction on the learning achievements and attitudes of organic chemistry students. Interdisciplinary Journal of Environmental and Science Education, 17(2), e2232. https://doi.org/ 10.21601/ijese/9330

\section{ARTICLE INFO}

Received:

22 June 2020

Accepted:

15 September 2020

\section{ABSTRACT}

Supplemental Instruction (SI) has been a successful implementation into Colleges and Universities across the globe. SI has been found to reduce attrition and improve learning and success rate among participating students. At the City College of New York, we recently implemented SI into Organic Chemistry I courses to further support struggling students with the content and concept learning of Organic Chemistry, which is considered a difficult course with a high attrition rate. Our motivation for this research was to examine the impact of SI integration in a large lecture format Organic Chemistry course while assisting students learn and succeed in this challenging course. The objective of this research is to examine whether supplemental instruction (SI) impacts participants' learning achievement, attitudes, and learning competencies. The experimental design was based on a quasi-experimental approach which included a questionnaire of open-ended and Likert-scaled questions that was distributed to SI participants, and SI participants' grades were compared to the grades of non-SI participants. Data suggest that integrating Supplemental Instruction (SI) into Organic Chemistry courses positively impacts students' attitudes towards the content and experience in the course, helps them better understand concepts and materials, improves students' problem-solving skills, and is effective in improving students' achievement, success, and the learning. SI participants had an overall passing average of $81 \%$, compared to about $50 \%$ for non-SI participants. SI participation provided the participants with a unique and individualized learning experience that resulted in an enhanced conceptual understanding.

Key words: chemistry education research, supplemental instruction, collaborative/cooperative learning

\section{INTRODUCTION}

Organic Chemistry is a required course for most science, some engineering, pharmacy, and pre-health majors. It is a challenging course that can deter undergraduate students from persisting in science. Organic Chemistry is a course feared by a majority of students and has a reputation of being a barrier to their academic careers. Its reputation as a barrier course has to do with the students' perceptions of it, how faculty members refer to it, and its teaching methodology is aimed at high achieving students (Seymour \& Hewitt, 1997). Classes that have more than 100 students enrolled are defined as large classes (Toby, 1998). Most universities and colleges now offer Organic Chemistry courses as large classes to be cost effective. Organic Chemistry has the characteristics of a high-risk or difficult course because it requires significant amount of readings, few tests that targets higher cognitive levels, voluntary attendance, and little interaction with instructor due to class size (Arendale, 1994).

The Supplemental Instruction (SI) model was initiated at the University of Missouri - Kansas City to address high attrition rates for some courses. As a result of the improved course grades and better retention, the model was extended to other courses (Burmeister et al., 1996). SI is a collaborative learning model that is part of the course. It is a type of academic support based on peer-assisted learning. SI has been implemented in more than 29 countries and 1,500 institutions (Martin, 2009). It targets traditionally difficult courses with 30 percent or higher $D$, W, and F grades (Arendale, 1994). Sl is a regularly scheduled workshop that supports students learning by going over problems in a cooperative learning setting led by a peer 
instructor (Martin \& Arendale, 1992). Furthermore, it has been shown to increase retention and graduation rates, as well as, improve grades for participants (Congos \& Schoeps, 1993). In one study, researchers found evidence that SI can be used to improve learning and as an effective teaching strategy (Ning \& Downing, 2010).

SI has been used across college campuses to increase retention and success rates in challenging courses that have high attrition rates (Widmar, 1994). The US Department of Education recognized the SI model as an exemplary program worthy of replication at postsecondary education institutions (Martin \& Arendale, 1993). Supplemental Instruction has been found to increase overall grades and decrease failure, attrition, and withdrawal grades in accounting students (Etter et al., 2000). Their research data shows that SI improves students' retention and learning achievement. SI participants have been found to have higher grade point averages than their peers, improved and team work and communication skills, increased retention rates, and increased motivation (Bowles et al., 2008). Several studies have shown that $\mathrm{SI}$ is an effective strategy in improving undergraduate academic achievement (McGuire, 2006).

SI participants attend sessions that helps them modify their own learning processes to become active learners based on their group interactions and social interdependence which promote cognitive development (Piaget, 1977; Vygotsky, 1978 \& 1986). Students in SI are actively involved in the learning processes as compared to passive participants in traditional lecture format (Hurley et al., 2006). Moreover, working in a group setting, students are more engaged and can benefit from each other which increases motivation and improves learning for each member of the group (Dion et al., 2007). SI participants work collaboratively to learn content, discuss course concepts and their relationships to each other, and engage in problem solving.

SI instructors are recruited from a pool of students who have completed the course and received an excellent grade. They are trained as peer leaders and supervised by the course instructor. The SI leaders do not lecture or solve problems. They work on facilitating discussions, group work, and problem solving with the students. The SI participants work collaboratively to reason through problems and solve them while helping one another (Bodner \& McMillen, 1986). Furthermore, SI leaders encourage participation and verbal discussions amongst the group members (Stanford \& Roark, 1974).

Research has demonstrated that SI attendance impacts students' overall learning achievement in their freshman year and the SI participants gain study strategies and skills that leads to improved academic achievement in other courses (Malm et al., 2012). Bowles and co-workers reported that students who participated in SI as freshmen improved their chances of graduating on time (Bowles et al., 2008). Researchers also found that students who participated in SI as freshmen successfully completed more course credits that those non-participants (Malm et al., 2010). SI participants received higher grades and lower withdraw grades than non-SI participants even though they had lower potential for academic success based on college admissions criteria (Congos \& Schoeps, 1993). Research data argues that SI fosters study habits and enhances motivation and learning of challenging concepts (Grillo \& Leist, 2013). Moreover, Ogden and coworked research shows that students who participated in SI had improved short- and long-term outcomes compared to those who did not participate in SI (Ogden et al., 2003).

\section{METHODS AND CONTEXT OF STUDY Study Background and Participants}

SI was implemented into The City College of New York (CCNY) in General Chemistry courses in 2017 and produced positive results on student learning achievement of SI participants (Author, 2019). CCNY is an urban minority serving institute that serves commuter students in New York City. We implemented SI into the first semester of Organic Chemistry (Organic Chemistryl) classestoexamine whether at risk-students can benefit from the program in the fall and spring of 2019 and 2020, respectively. The Organic Chemistry I course is composed of a traditional lecture component and recitation component run with the spirit of Peer Led-Team Learning (PLTL). PLTL is an integrated part of the course (Lewis, 2011). Our study is unique because we are targeting students who are struggling in the course to provide another support and learning platform. SI instructors targeted weaknesses in study habits, socialization, conceptual-understanding, and problem-solving skills.

\section{SI Implementation Approach}

SI was made available every day the Organic Chemistry courses met which was four days a week. This makes it easier for students with busy schedules to attend SI sessions. We designed our SI sessions to allow students to work collaboratively, discuss concepts, address misconceptions, and problem-solve (Rath et al., 2007). We should note that during the spring of 2020 after the COVID-19 outbreak, SI was moved to Blackboard Collaborate Ultra and our attendance improved which might have to do with more students feeling anxious and struggling with course material.

Our SI sessions were proactive to encourage students 
to attend. SI schedules were set during the first week of classes so students could receive help before they course material they need to learn becomes monumental. SI attendance is voluntary and students who are struggling in the course are especially encouraged to participate. SI instructors are recruited from academically high achieving students who have completed Organic Chemistry with excellent grades. SI instructors are trained PLTL leaders and designed their sessions where they encouraged and facilitated students' interactions, support, and engagement. SI leaders receive training as PLTL leaders which includes helping students improve learning skills. SI leaders do not provide answers or lecture. They facilitate learning and allowing students to discuss and reason through problems. SI leaders work with students on developing their meaningful learning capabilities and moving away from rote-learning (Ausubel et al., 1978).

\section{Research Design}

Our motivation for this research was to examine the impact of SI integration in a large lecture format Organic Chemistry course while assisting students learn and succeed in this challenging course. Our research project is unique due to the fact that no studies to date are available using $\mathrm{SI}$ in organic chemistry. Furthermore, we wanted to study whether at-risk students can benefit from this approach. We should mention that our course now has three components: traditional large-lecture part, recitation part run in the spirit of PLTL format, and Supplemental Instruction. PLTL engages students in problem-solving activities and facilitates discussion or content (Gafney \& Varma-Nelson, 2008). While the lecture and PLTL are integrated and part of the course for all students, $\mathrm{SI}$ is voluntary and used to recruit and assist at-risk, struggling students in the course.

\section{Guiding Research Questions}

1. Does Supplemental Instruction impact participants' learning achievement?

2. What are the Supplemental Instruction participants' views and attitudes about the SI experience?

3. Does SI influence participants' knowledge and competencies?

\section{Development of Evaluation Instrument}

In order to properly assess the impact of integrating SI into organic chemistry, we used a quasi-experimental approach to measure the effect of the intervention on participants. We collected data from a survey that was handed out to SI participants that contained a fivepoint Likert questionnaire and open-ended questions. Additionally, we examined the grades earned in the course for comparison between SI and non-SI participants. Our survey was in compliance and had the approval of our Internal Review Board (IRB). It is noteworthy that even though the survey was optional, 90 out of the $133 \mathrm{SI}$ participants completed the survey.

\section{Data Analysis}

To make sense of the data, we took an average from the respondents answers for each Likert-type question. A rubric was created and used for the open-ended questions and an average was taken from answers of respondents. Bar graphs were created based on the data obtained. For one of the questions, we compiled the answers and created pie charts based on the type and percentage of responses.

\section{RESULTS}

Participation in SI sessions was 133 students out of 400 despite the repeated attempts to get more students to participate in the SI sessions. SI participants had an overall passing average of $81 \%$, compared to about $50 \%$ for non-SI participants.

The data in Table 1 show that students believe that SI has helped them improve their problem-solving skills, how to go about solving organic chemistry problems, better understand organic chemistry concepts covered in lecture, and understand and reinforce the concepts learned in organic chemistry class. Furthermore, the data collected from students show that the students' perception of SI leaders is that they were very helpful and that SI provided an opportunity to practice problems outside the formal classroom environment. Students viewed SI as worth the time and effort and was overall beneficial and contributed to their improvement in the course grade. Finally, their overall experience with SI was extremely positive. We should mention that the Likerttype questions averaged more than 4.73 for all questions and overall the questions averaged 4.83 .

Figure 1 presents the data based on open-ended questions. The figure shows that the students believe that SI helped them better understand concepts in organic chemistry and that they would highly recommend it to other students. Their description of their SI experience was a positive one.

Figure 2 is a pie chart showing the benefits the students received from being involved in SI. $48 \%$ of students appreciate the time spent on practicing problems, $19 \%$ cited the importance of individualized attention they received during SI sessions, 15\% mentioned the slow pace/ not rushed that the SI sessions provided, which is often contrary to the lecture that has to cover so many topics, and $18 \%$ valued the importance of group work, where 
Table 1. Questions and averages for the answers for the Likert-type questionnaire

$\begin{array}{ll}\text { Likert-Type Question } & \text { Average Answer from } \\ \text { Respondents }\end{array}$

Supplemental Instruction has helped me to improve my basic organic chemistry problem-solving skills.

Supplemental Instruction helped me to better understand how to go about solving an organic chemistry problem.

Supplemental Instruction leaders were able to target my weak areas in organic chemistry and help me improve on them.

Supplemental Instruction encouraged me to practice more outside of class time.

Supplemental Instruction helped me to better understand organic chemistry concepts covered in lecture.

Supplemental Instruction helped me better understand the organic chemistry course material.

Supplemental Instruction was worth the time and effort I put into it.

Supplemental Instruction was overall beneficial to me and contributed to my improvement in the course grade.

Doing problems during Supplemental Instruction helped me understand and reinforce the concepts learned in organic chemistry class.

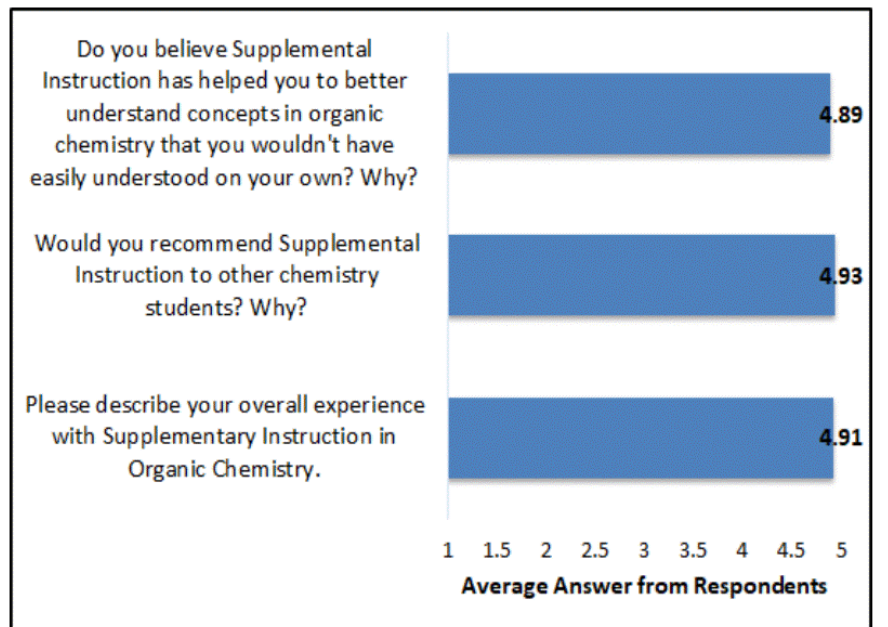

Figure 1. Averages of the short-answer responses were numerically scaled using a rubric

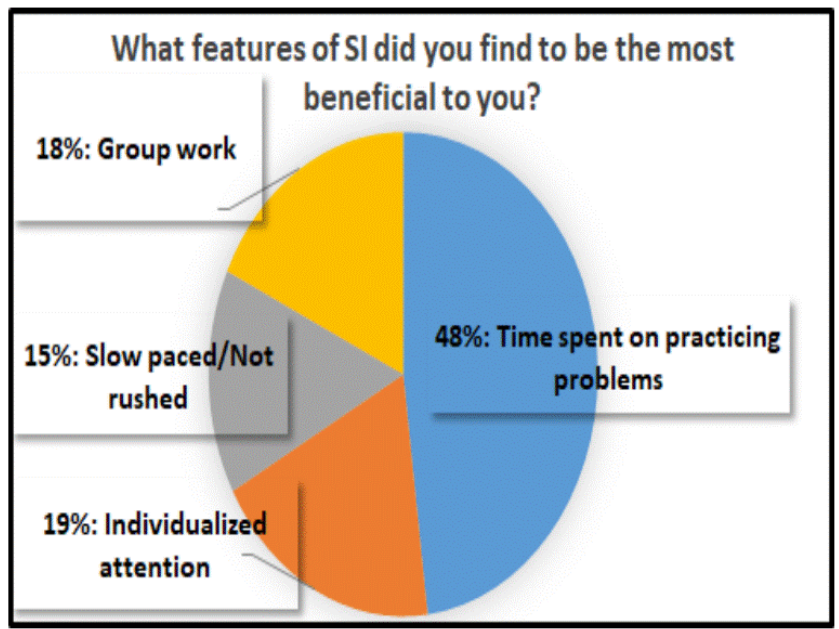

Figure 2. Pie chart of the beneficial components of SI to students 
they are involved in social learning. Researchers highlight the importance of social learning and engagement in SI sessions which allows for the creation of physical, safe, and cognitive spaces for learning chemistry (Paideya \& Sookrajh, 2014).

\section{DISCUSSION}

Our data suggests that students underscore the importance of group work. Students worked collaboratively on solving problems where the SI instructor helped facilitate the learning process. Research findings suggest that when students explain concepts in their own words and being engaged in discussions with other students led to an improved understanding of the concepts of stoichiometry (Paideya \& Sookrajh, 2010). We actively recruited students, through announced by faculty instructors, PLTL leaders, SI leaders, and blackboard, who were struggling in learning the course material and can be referred to as at-risk students. One of the issues that we encountered with implementation of SI into Organic Chemistry is that we could not reach more of the students to convince them to participate and attend SI sessions, which could be attributed to lack of interest on the students' part, insufficient motivation, or deficiency in buying into the philosophy of SI. Students that we managed to recruit outperformed on learning achievement those who did not participate in SI session. Research on nursing students and SI shows that there is evidence of impact on at-risk students' achievement and academic success (Harding, 2012). Furthermore, studies on $\mathrm{SI}$ in introductory biology course show that it is beneficial to at-risk students and help them improves academic achievement and enhance their positive academic behaviors (Moore \& LeDee, 2006).

The cost of running SI sessions at the City College of New York was about eighty dollars per student which is cost efficient. This is considered a small price to pay to solve the problems of attrition and failure rates in those large lecture challenging courses. $\mathrm{SI}$ is a cost effective program where students work collaboratively on discussing course's content and concepts and on problem solving which helps them improve learning and achievement in chemistry (Lundeberg, 1990).

The research data suggest that the students had a positive learning experience and improved learning outcomes for the participants. This could be attributed to the fact that working collaboratively with their peers relieved some of the stresses of learning challenging content and created comradery within the participants. This is supported by at least one research study where the data suggest that SI positively impact students' learning experience and increases their engagement with learning of the content (Bengesai, 2011). SI provides students with the opportunity to develop conceptual understanding of the course's content and improve their learning and study habits. According to Bronstein (2008), SI participation is voluntary and has positively impacted academic achievement in Physical Chemistry.

SI sessions were held for 14 times during the semester. The majority of SI participants attended and participated in most if not all of these sessions based on attendance that SI leaders took and kept for every session. Some students participated less frequently. Actually, there were a few students who participated in just one session. For purposes of this research, we did not include data from students who participated in $\mathrm{SI}$ in only four sessions or less. Researchers have found that students who attended the minimum required number of SI session were found to outperform those who did not meet this criterion (Carlsen-Landy et al., 2014).

Participation in $\mathrm{SI}$ session was about 33\%, 133 students out of 400 despite the repeated attempts to get more students to participate in the SI sessions. We should note that CCNY failure rate, students who do not receive $A B C$ grades, is about $50 \%$. Despite the fact that $\mathrm{SI}$ participation dramatically increases students' academic achievement, many are still reluctant to attend the sessions regularly (Arendale, 1994). Researchers reported issues with low participation at commuter campuses like ours at CCNY and their results also is consistent with ours in that SI participants had a higher grade achieved than their non-SI counterparts (Altomare \& Moreno-Gongora, 2018).

Some of the limitations of this study are that the data in this study was collected from one urban, minority serving institution, where the students come from a wide range of backgrounds and we did not account for this in our data analysis, and collection of data on student learning is quite complex as a topic and to study. It can be arduous to obtain enough detailed data and insights on students' learning and understanding of organic chemistry from a questionnaire. More detailed data and in depth interviews would make a reasonable future study. Another limitation could be the fact that students self-select to participate in SI which might indicate that more motivated students participated in SI sessions.

It is noteworthy that SI participants, who sought SI because they were struggling in the course, had an overall passing average of $81 \%$, compared to about $50 \%$ for nonSI participants. This data is consistent with other research where SI participation has been found to improve students' success in calculus course where students' passing rate was found to be $79 \%$ compared to $39 \%$ for non-SI participants (Malm et al., 2011). Our data shows 
that students participating in SI sessions outperformed non-SI students and that they had a positive learning experience with $\mathrm{SI}$, which could be attributed to the fact that SI participants were more motivated. This is supported by other research in the field where it was found that SI participants consistently outperformed nonSI students, SI participants liked the SI experience found it helpful in preparation for the obstacles in the course (Kalil et al., 2016). Forester and co-authors reported on SI programs on medical students and found that they earn higher grades and higher levels of satisfaction which is consistent with our results and data (Forester et al., 2004).

SI participants received overall more $\mathrm{A}, \mathrm{B}$, and $\mathrm{C}$ grades compared to non-SI participants and this led to increased success rates for SI participants. This is supported by other studies where the authors found that SI participants earned a higher percentage of $A$ and $B$ grades and lower percentage of $D, W$ and $F$ grades than non-SI participants in biology, chemistry, mathematics and physics (Hensen \& Shelley, 2003). They also report that SI participants had lower admission scores than non-SI participants. In another study, data shows that SI participation significantly increased grades and passing rates compared to non-SI participants. We should note that this study accounted for controlling other non-academic factors (Birkett et al, 2017). In one study, chemistry courses by the same instructor were compared and it was reported that the course where SI was implemented the grades were significantly higher (Carlsen-Landy et al., 2014). Finally, SI research on a biology course show that students had higher final course grades than the non-SI students (Congos \& Schoeps, 1998). These research data are in line with our own data and results which showed that students' learning achievement was positively impacted as evident by the higher percentages of $A, B$, and $C$ grades for SI participants.

\section{CONCLUSIONS}

The research data suggests that integrating Supplemental Instruction (SI) into Organic Chemistry courses results in a positive impact on students' attitudes towards the content and experience in the course. SI helped them better understand concepts and materials in the course and provided a platform for struggling students to learn from one another and discuss the concepts with peers and SI instructors in a collaborative learning environment.

Our research data suggests that SI improves students' problem-solving skills and understanding of organic chemistry concepts. Furthermore, it allows students to reinforce the concepts learned during the lecture and provides an opportunity to practice problems collaboratively while providing a facilitative learning environment and the time needed to think, discuss, and solve problems. Students' views of SI sessions were positive and they enjoyed the learning sessions, individualized attention, and collaborative study groups.

Based on the final grades in Organic Chemistry and the responses to a questionnaire, Supplemental Instruction was effective in improving students' achievement, success, and the learning experience. SI participants had an overall passing average of $81 \%$, compared to about $50 \%$ for non-SI participants. SI participation provided the participants with a unique and individualized learning experience that resulted in an enhanced conceptual understanding of the challenging organic chemistry concepts and improved study habits. The resulted in an increased achievement and success for SI participants as compared to non-SI students. SI positively impacts participants' learning achievement as well as their views and attitude with the SI experience.

\section{REFERENCES}

Altomare, T. K., \& Moreno-Gongora, A. N. (2018). The role and impact of Supplemental Instruction in accelerated developmental math courses. Journal of College Academic Support Programs, 1(1), 19-24. https://digital.library.txstate. edu/handle/10877/7912

Arendale, D. R. (1994). Understanding the supplemental instruction model. New Directions for Teaching and Learning, 60, 11-21. https://doi:10.1002/tl.37219946004

Ausubel, D. P., Novak, J., \& Hanesian, H. (1978). Psychology: A Cognitive view. Austin, Tex.: Holt, Rinehart and Winston.

Bengesai, A. (2011). Engineering students' experiences of Supplemental Instruction: A case study. Alternation, 18(2), 59-77.

Birkett, M., Neff, L., \& Deschamps, E. (2017). Low high school GPA: Another reason to try SI. Supplemental Instruction Journal, 3(1), 24-37.

Bodner, G. M., \& McMillen, T. L. (1986). Cognitive restructuring as an early stage in problem solving. Journal of Research in Science Teaching, 23(8), 727-737. https://doi.org/10.1002/ tea.3660230807

Bowles, T. J., McCoy, A., \& Bates, S. (2008). The effect of supplemental instruction on timely graduation. College Student Journal, 42(30), 853-859.

Bronstein, S. B. (2008). Supplemental instruction: Supporting persistence in barrier Courses. The Learning Assistance Review, 13, 31-45.

Burmeister, S., Kenney, P., \& Nice, D. (1996). Analysis of effectiveness of SI sessions for college algebra, calculus, and statistics. In Research in collegiate mathematics education II (pp. 145-154). Providence, RI: American Mathematical Society.

Carlsen-Landy, B., Falley, B., Wheeler, A., \& Edwards, D. (2014). Adaptations of Supplemental Instruction: Our course assistants wear many hats. Supplemental Instruction Journal, 1(1), 7-21.

Congos, D. H., \& Schoeps, N. (1993). Does supplemental instruction really work and what is it anyway? Journal of 
Teaching \& Learning, 18(2), 165-176. https://doi.org/10.1080/ 03075079312331382349

Congos, D. H., \& Schoeps, N. (1998). Inside Supplemental Instruction Sessions: One model of what happens that improves grades and retention. Research and Teaching in Developmental Education, 15(1), 47-81.

Dion, E., Fuchs, D., \& Fuchs. L. S. (2007). Peer-mediated programs to strengthen classroom instruction: Cooperative learning, reciprocal teaching, class-wide peer tutoring, and peer-assisted learning strategies. In Handbook of special education, ed. L. Florian, 450-59. London: Sage.

Etter, E. R., Burmeister, S. L., \& Elder, R. J. (2000). Improving student performance and retention via supplemental instruction. Journal of Accounting Education, 18(4), 455-368. https://doi.org/10.1016/S0748-5751(01)00006-9

Forester, J. P., Thomas, P. P., \& McWhorter, D. L. (2004). Effects of four Supplemental programs on students' learning of gross anatomy. Clinical Anatomy, 17(4), 322-327.

Gafney, L., \& Varma-Nelson, P. (2008). Peer-led team learning: Evaluation, dissemination, and institutionalization of a college level initiative. Dordrecht, The Netherlands: Springer.

Grillo, M. C., \& Leist, C. W. (2013). Academic support as a predictor of retention to graduation: New insights on the role of tutoring, learning assistance, and supplemental instruction. Journal of College Student Retention: Research, Theory \& Practice, 15(3), 387-408. https://doi.org/10.2190/ CS.15.3.e

Harding, M. (2012). Efficacy of supplemental instruction to enhance student success. Teaching and Learning in Nursing, 7, 27-31.

Hensen, K. A., \&Shelley, M. C. (2003). The impact of Supplemental Instruction: Results from a large, public, Midwestern university. Journal of College Student Development, 44(2), 250-259. https://DOI:10.1353/csd.2003.0015

Hurley, M., Jacobs, G., \& Gilbert, M. (2006). The basic SI model. New Directions for Teaching and Learning, 106, 11-22. https:// doi.org/10.1002/tl.229

Kalil, A., Jones, C., \& Nast, P. (2016). Application of Supplemental Instruction in an undergraduate anatomy and physiology course for allied health students. Supplemental Instruction Journal, 2(1), 33-52.

Lewis, E. S. (2011). Retention and reform: An evaluation of peerled team learning. Journal of Chemical Education, 88(6), 703707. https://doi.org/10.1021/ed100689m

Lundeberg, M. A. (1990). Supplemental Instruction in Chemistry. Journal of Research in Science Teaching, 27(2), 145-155. https://doi.org/10.1002/tea.3660270206

Malm, J., Bryngfors, L., \& Mörner. L. (2010). Supplemental instruction (SI) at the Faculty of Engineering (LTH), Lund University, Sweden. An evaluation of the SI program at five LTH engineering programs, Autumn 2008, Australian Journal of Peer Learning, 3(1), 38-50. https://ro.uow.edu.au/ ajpl/vol3/iss $1 / 5$

Malm, J., Bryngfors, L., \& Mörner, L. (2011). Supplemental Instruction: Whom Does it Serve? International Journal of Teaching and Learning in Higher Education, 23(3), 282-291.

Malm, J., Bryngfors, L., \& Mörner, L. (2012). Supplemental instruction for improving first-year results in engineering studies. Studies in Higher Education, 37(6), 655-666. https:// DOI:10.1080/03075079.2010.535610

Martin, D. (2009). Foreword. Australasian Journal of Peer Learning, 1(1), 3-5. https://ro.uow.edu.au/ajpl/vol1/iss1/2

Martin, D. C., \& Arendale, D. A. (1992). Supplemental Instruction:
Improving First-Year Student Success in High-Risk Courses, 2nd ed.; Monograph Series no. 7; South Carolina University: Columbia, SC.

Martin, D. C., \& Arendale, D. A. (1993). Understanding the SI model. In D. Martin \& D. Arendale. Supplemental instruction: Improving first-year student success in high risk courses (pp. 3-10). Columbia, SC: National Resource Center for The Freshman Year Experience and Students in Transition.

McGuire, S.Y. (2006). The impact of supplemental instruction on teaching students how to learn. New Directions for Teaching and Learning, 106, 3-10. https://DOl:10,1002/ll.22H

Moore, R., \& LeDee, O. (2006). Supplemental instruction and the performance of developmental education students in an introductory biology course. Journal of College Reading and Learning, 23(2), 9-20. https://doi.org/10.1080/10790195 .2006.10850184

Ning, H. K., \& Downing, K. (2010). The impact of supplemental instruction on learning competence and academic performance. Studies in Higher Education, 35(8), 921-939. https://DOI:10.1080/03075070903390786

Ogden, P., Thompson, D., Russell, A., \& Simons. C. (2003). Supplemental instruction: Short-and long-term impact. Journal of Developmental Education, 26, 2-8.

Paideya, V., \& Sookrajh, R. (2010). Exploring the use of supplemental instruction: Supporting deep understanding and higher-order thinking in Chemistry. South African Journal of Higher Education, 24(5), 758-770. https://hdl. handle.net/10520/EJC37643

Paideya, V., \& Sookrah, R. (2014). Student engagement in chemistry Supplemental Instruction: Representations of learning spaces. South African Journal of Higher Education, 28(4), 1344-1357. https://doi.org/10.20853/28-4-398

Piaget, J. (1977). The moral judgment of the child. London: Penguin.

Rath, K. A., Peterfreund, A. R., Xenos, S. P., Bayliss, F., \& Carnal, N. (2007). Supplemental instruction in introductory biology I: Enhancing the performance and retention of underrepresented minority students. CBE-Life Sciences Education, 6(3), 203-216. https://DOl:10.1187/cbe.06-10$\underline{0198}$

Salame, I. I., \& Nazir, R. (2019). The impact of supplemental instruction on the performance and attitudes of general chemistry students. International Journal of Chemistry Education Research, 3(2), 53-59. https://doi.org/10.20885/ ijcer.vol3.iss2.art1

Seymour, E., \& Hewitt, N. (1997). Talking about leaving: Why undergraduates leave the sciences. Boulder, CO: Westview Press.

Stanford, G., and Roark, A. E. (1974). Human interaction in education. Boston: Allyn \& Bacon, Inc.

Toby, S. (1998). The relationship between class size and students, ratings of faculty: Or why some good teachers should not teach general chemistry. Journal of Chemical Education, 76, 788-790. https://DOI:10.1021/ed065p788

Vygotsky, L.S. (1978). Mind in society. Cambridge, MA: Harvard University Press.

Vygotsky, L.S. (1986). Thought and language. Cambridge, MA: MIT Press. (Orig. pub. 1934.)

Widmar, G. (1994). Supplemental instruction: from small beginnings to national program. New Directions for Teaching and Learning, 60, 3-10. https://doi.org/10.1002/ $\mathrm{tl} .37219946003$ 